\title{
Efeito do tiadiazuron na micropropagação in vitro de dois genótipos de mamona via organogênese ${ }^{1}$
}

\author{
Carla S. N. Ribeiro ${ }^{2}$, Humberto Silva ${ }^{3}$, José W. dos Santos ${ }^{4} \&$ Julita M. F. C. Carvalho ${ }^{4}$
}

RESUMO

Propôs-se, com esta pesquisa, avaliar a indução de multibrotações nos genótipos de mamona BRS N ordestina e CSRN 142, no explante gema apical, determinando-se o melhor tratamento com o fitorregulador Tiadiazuron (TDZ) e indicar a concentração satisfatória do ácido-3-indolacético (AIA) para o enraizamento ex vitro. Utilizou-se o meio Murashige e Skoog, suplementado com TDZ nas concentrações 0 (testemunha) 0,5; 1,0; 2,0; 5,0 e 10,0 $\mathrm{mg} \mathrm{L}^{-1}$, com três explantes por frasco, em um delineamento inteiramente casualizado. As avaliações foram realizadas após 45 dias de cultivo analisando-se o número de brotos por explante e a porcentagem de necrose. No enraizamento ex vitro fez-se uso do AIA, nas concentrações $0 ; 0,125 ; 0,25 ; 0,5$ e 1,0 $\mathrm{g} \mathrm{L}^{-1} \mathrm{e}$ do substrato de aclimatação (turfa + vermiculita). 0 bservou-se que a concentração de $0,5 \mathrm{mg} \mathrm{L}^{-1} \mathrm{de}$ TDZ proporcionou a melhor proliferação in vitro, alcançando até 16,9 brotos por explante. No enraizamento ex vitro o tratamento mais promissor foi turfa + vermiculita $+0,125 \mathrm{~g} \mathrm{~L}^{-1}$ de AIA, com 75\% de plantas enraizadas. Verificou-se que o TDZ induz o superbrotamento nos dois genótipos e o enraizamento ex vitro é uma alternativa viável aos programas de melhoramento vegetal.

Palavras-chave: Ricinus communis,_biotecnologia, fitorreguladores

\section{Effect of the thidiazuron in vitro micropropagation of two castor bean genotypes by organogenesis}

\begin{abstract}
The objective of this research was to evaluate the effectiveness to induce the multiplication of shoots in the BRS Nordestina and CSRN 142 castor bean genotypes, in the explant apical meristem, determining the best treatment with the thidiazuron (TDZ) growth regulator and to indicate the satisfactory concentration of the indoleacetic acid (AIA) for the ex vitro rooting. The Murashige and Skoog medium, was used supplemented with TDZ in the concentrations 0 (control); 0.5, 1.0, 2.0, 5.0 e $10.0 \mathrm{mg} \mathrm{L}^{-1}$, with three explants per flask, in randomized blocks. The evaluations were made after 45 days of cultivation, being analyzed the number of brunches for explant and the percentage of necrosis. In the ex vitro rooting, the use of AIA was made, in the concentrations $0,0.125,0.25,0.5$ and $1.0 \mathrm{~g} \mathrm{~L}^{-1}$ in the acclimatization substrate. It was observed that the concentration of $0.5 \mathrm{mg} \mathrm{L}^{-1}$ of TDZ provided the best results in vitro proliferation, reaching 16.9 brunch for explant. In the ex vitro rooting, the most promising treatment was substrate $+0.125 \mathrm{~g} \mathrm{~L}^{-1}$ of AIA, with $75 \%$ of rooted plants. It was verified that the TDZ induces the over brunching in the two genotypes and that the ex vitro rooting is a viable alternative for the programs of plants improvement.
\end{abstract}

Key words: Ricinus communis, biotechnology, growth regulators

\footnotetext{
1 Parte da monografia de graduação da primeira autora, apresentada ao PIBIC-CN Pq-UEPB

2 Mestranda do PPGAM GP/U FRPE, bolsista do CN Pq. Av. Dom Manoel de Medeiros s/n, Bairro Dois Irmãos, CEP 52171-900, Recife, PE. Fone: (81) $3320-6313$. E-mail: carlasibere@gmail.com

3 Departamento de Biologia/U EPB. Av. das Baraúnas 351, Campus U niversitário, Bodocongó, CEP 58109-753, Campina Grande, PB. Fone: (83) 3343 1205. Email: humbertoecologia@bol.com.br

${ }^{4}$ Embrapa Algodão. Rua Osvaldo Cruz 1143, Centenário, CEP 58107-720, Campina Grande, PB. Fone: (83) 3315 4341. E-mails: jwsantos@cnpa.embrapa.br; julita@cnpa.embrapa.br
} 


\section{INTRODUÇãO}

A mamoneira (Ricinus communis L.) é uma das principais oleaginosas do mundo e se vem destacando como ótima alternativa de exploração para o agronegócio no Brasil, em especial para a região nordeste, com a possibilidade do óleo da mamona ser matéria-prima para a produção do biodiesel (Beltrão et al., 2003).

Mesmo sendo uma planta rústica, com grande capacidade de adaptação a todas as regiões do Brasil, o cultivo da mamona é bastante afetado por vários micro-organismos, tais como fungos, bactérias e vírus, que podem causar prejuízos de grande expressão econômica, caso as condições climáticas sejam favoráveis ao seu desenvolvimento. O mofo-cinzento é a principal doença da mamoneira, cujo agente etiológico é o fungo Botrytis ricini Godfrey, que causa grandes prejuízos à produção, pois destrói inflorescências e cachos, reduzindo a produção de óleo pela diminuição dos frutos colhidos (Milani et al., 2005).

A micropropagação por meio da cultura de tecidos afasta os riscos de contaminação por micro-organismos, pela possibilidade de produzir plantas saudáveis e isentas de patógenos. A propagação vegetativa in vitro tem sido uma técnica bastante utilizada na mamoneira, em virtude de oferecer vantagens de manutenção de estoques de genótipos e fenótipos de híbridos, mutações genéticas selecionadas, intercâmbio de germoplasma e obtenção de clones de genótipos com caracteres agronômicos desejáveis, além de excelente estado fitossanitário (Carvalho, 1999).

Protocolos eficientes para a regeneração in vitro são fundamentais na utilização de técnicas de transformação genética, haja vista que a definição de parâmetros por meio da cultura de tecidos possibilita o desenvolvimento de transgênicos de culturas de importância econômica, como a mamoneira. Segundo Alves et al. (2004), o processo de organogênese é complexo, com atuação de múltiplos fatores externos e internos, envolvendo interação entre fonte de explante, meio de cultura e fatores do ambiente, dependendo também da ação de reguladores de crescimento exógenos, em particular auxinas e citocininas e da habilidade do tecido em responder a essas mudanças hormonais, durante o período de cultivo (Sugiyama, 1999).

De vez que o tiadiazuron é uma feniluréia com ação citocinínica de forte efeito na micropropagação, obtêm-se resultados satisfatórios, como no trabalho realizado por Furtado et al. (2007) no superbrotamento de amendoim.

Objetivou-se, com este trabalho, avaliar a indução de multibrotações nos genótipos de mamona BRS Nordestina e CSRN 142, no explante gema apical, determinando-se a melhor concentração do fitorregulador Tiadiazuron (TDZ) para o superbrotamento in vitro e indicar o tratamento adequado do ácido-3-indolacético (AIA) para o enraizamento ex vitro dos brotos.

\section{MATERIAL E MÉTODOS}

A pesquisa foi desenvolvida no Laboratório de Cultura de Tecidos do setor de Biotecnologia da Embrapa Algodão, em Campina Grande, PB.

Sementes de dois genótipos de mamona, BRS Nordestina e CSRN 142, foram previamente lavadas com água corrente e sabão neutro para eliminar contaminantes das quais se retirou, em seguida, o tegumento, como método de quebra da dormência, para facilitar a germinação; continuando, imergiram-se as sementes em solução de hipoclorito de sódio a 2,5\% de cloro ativo e se adicionou uma gota de tween 20 a cada $100 \mathrm{~mL}$ de solução, durante $20 \mathrm{~min}$; posteriormente, as sementes foram lavadas quatro vezes em água bidestilada estéril, para se retirar o excesso de hipoclorito de sódio, permanecendo imersas na última água, durante $24 \mathrm{~h}$.

Quando da obtenção da planta matriz após a esterilização das sementes na câmara de fluxo laminar e com auxílio de instrumentos cirúrgicos esterilizados, se excisaram os eixos embrionários e se inocularam em meio MS (Murashige \& Skoog, 1962) suplementado com $30 \mathrm{~g} \mathrm{~L}^{-1}$ de sacarose e $0,55 \%$ de ágar e se ajustou o pH para 5,8, utilizando-se hidróxido de sódio $(\mathrm{NaOH})$ ou ácido clorídrico (HCL) antes da autoclavagem, a $120^{\circ} \mathrm{C}$; em seguida, os tubos de ensaio contendo os explantes foram fechados com tampa de polipropileno e vedados com fita-filme enquanto as culturas permaneceram no escuro, pelo tempo de 48-72 h e posteriormente foram mantidas durante 25 dias em sala de aclimatação, com irradiância de $30 \mu \mathrm{mol} \mathrm{m}{ }^{-2} \mathrm{~s}^{-1}$, fornecida por lâmpadas fluorescentes brancas de $20 \mathrm{~W}$, até a formação da planta matriz.

As gemas apicais utilizadas como explante foram originadas a partir de plântulas cultivadas in vitro, com 20-25 dias após o plantio. Na câmara de fluxo laminar e com auxílio de instrumentos cirúrgicos esterilizados, os explantes foram separados e excisados e em seguida inoculados em meio básico MS, suplementado com a citocinina Tiadiazuron (TDZ), conforme os tratamentos: $\mathrm{T}_{0}(\mathrm{MS}), \mathrm{T}_{1}\left(\mathrm{MS}+0,5 \mathrm{mg} \mathrm{L}^{-1} \mathrm{de} \mathrm{TDZ}\right)$, $\mathrm{T}_{2}\left(\mathrm{MS}+1 \mathrm{mg} \mathrm{L}^{-1} \mathrm{de} \mathrm{TDZ}\right), \mathrm{T}_{3}\left(\mathrm{MS}+2 \mathrm{mg} \mathrm{L}^{-1} \mathrm{de} \mathrm{TDZ}\right), \mathrm{T}_{4}$ (MS + $5 \mathrm{mg} \mathrm{L}^{-1}$ de TDZ) e $\mathrm{T}_{5}\left(\mathrm{MS}+10 \mathrm{mg} \mathrm{L}^{-1}\right.$ de TDZ), somando-se seis diferentes tratamentos.

Todos os meios foram suplementados com 3\% de sacarose e $0,55 \%$ de ágar e o pH do meio ajustado para 5,8 antes da autoclavagem, a $120^{\circ} \mathrm{C}$; em todos os casos a incubação permaneceu a $25 \pm 2{ }^{\circ} \mathrm{C}$ com um fotoperíodo de $16 \mathrm{~h}$ de luz e intensidade luminosa de $30 \mu \mathrm{mol} \mathrm{m}^{-2} \mathrm{~s}^{-1}$; enfim, o subcultivo foi realizado a cada 15 dias.

$\mathrm{Na}$ avaliação se analisou, após 45 dias de cultivo em meio com presença da citocinina TDZ, a resposta dos tratamentos utilizados, considerando-se o parâmetro NBE (número de brotos por explante) e, como superbrotados, apenas os explantes que obtiveram mais de dois brotos; depois de avaliados os explantes com múltiplos brotos foram transferidos para o meio básico MS sem fitorreguladores e, decorridos 15 dias, com a giberelina $\mathrm{GA}_{3}$ na concentração de $0,5 \mathrm{mg} \mathrm{L}^{-1}$, para o alongamento dos brotos.

Os dados referentes ao número de brotos por explante foram submetidos a análise de variância, as médias trans- 
formadas em $\mathrm{y}=\sqrt{x+1}$, para estabilização das variâncias dos erros experimentais e analisadas mediante o procedimento PROC GLM do "SAS", versão 8.2 (SAS/STAT, 2000), e só então foram comparadas pelo teste de Tukey, a $5 \%$ de probabilidade.

Os brotos de mamona obtidos in vitro e que passaram por um alongamento de 1 a $3 \mathrm{~cm}$, foram selecionados e excisados; em seguida, mergulhados 1 min em soluções contendo a auxina ácido-3-indolacético (AIA), nas concentrações: 0,0; 0,$125 ; 0,25 ; 0,5$ e $1,0 \mathrm{~g} \mathrm{~L}^{-1} \mathrm{e}$, finalmente, eles foram cultivados diretamente em copos plásticos de $250 \mathrm{~mL}$, contendo substrato de aclimatação (turfa + vermiculita), na proporção 2:1, já esterilizado durante $1 \mathrm{~h}$, na autoclave a $120^{\circ} \mathrm{C}$. Utilizou-se 1 broto para cada recipiente com substrato. As bandejas contendo os copos plásticos foram transferidas para a sala de aclimatização, a $25 \pm 2{ }^{\circ} \mathrm{C}$, com um fotoperíodo de $16 \mathrm{~h}$ de luz e intensidade luminosa de $30 \mu \mathrm{mol} \mathrm{m} \mathrm{m}^{-2} \mathrm{~s}^{-1}$.

As avaliações do enraizamento foram efetuadas 40 dias após a inoculação, observando-se as seguintes variáveis: número de plantas enraizadas (NPR) e número de plantas mortas (NPM).

Para o superbrotamento o delineamento experimental utilizado foi o inteiramente casualizado no arranjo fatorial 2 × 6 (2 tipos de explante e 6 tratamentos) utilizando-se 15 frascos por tratamento, com três explantes por frasco e, para o enraizamento, utilizou-se um delineamento experimental inteiramente casualizado, no esquema fatorial 1 × 2 × 5 (1 tipo de explante, dois genótipos e 5 tratamentos) com 4 repetições por tratamento; o conjunto de quatro copos constituiu a unidade experimental submetida aos diferentes tratamentos, cujos resultados foram expressos em porcentagem dos parâmetros número de plantas enraizadas e número de plantas mortas.

\section{RESULTADOS E DISCUSSÃO}

\section{Desinfestação das sementes e formação da planta matriz}

A metodologia descrita foi bastante eficaz ocasionando contaminação de apenas (1\%) na BRS Nordestina e baixa contaminação (5\%) na CSRN 142; constatou-se alto índice de formação de plantas matrizes saudáveis e vigorosas, ou seja, 99 e 95\% para os dois genótipos, BRS Nordestina e CSRN 142, respectivamente. Os dados comprovaram que a metodologia aplicada neste estudo é recomendável e eficiente. Segundo Leifert et al. (1991), a condição fitossanitária da planta determina a eficiência no processo de desinfestação dos explantes.

Tal como neste trabalho, Rocha et al. (2003) desinfestaram sementes de mamona a $2,5 \%$ de cloro ativo, durante $20 \mathrm{~min}$, utilizando também diferentes lavagens das sementes em água bidestilada estéril, quando então obtiveram resultados semelhantes aos indicados na presente pesquisa.

A excisão dos eixos embrionários após a desinfestação das sementes facilitou a obtenção de explantes de qualidade superior para a micropropagação in vitro, em virtude de sua natureza juvenil, com alto potencial regenerativo. A utilização do embrião em estudos de superbrotamento do amendoin (Arachis hipogaea L.), também foi favorável ao estabelecimento in vitro (Carvalho et al., 2003).
Resultados diferentes aos do eixo embrionário, ocorreram em estudos de morfogênese para a cultura da mamoneira, em que se utilizaram sementes inteiras na semeadura in vitro, com grande dificuldade para obtenção de plantas matrizes, devido à lentidão, baixa porcentagem de germinação e ao alto teor de contaminação das sementes (Carvalho, 2002).

\section{Indução de múltiplos brotos - genótipo BRS Nordestina}

As respostas obtidas com a indução de número de brotos por explante (NBE) em todas as concentrações utilizadas no explante gema apical, estão expostas na Tabela 1, na qual se verificam as melhores médias de brotos por explante no $\mathrm{T}_{1}$ (MS + 0,5 $\mathrm{mg} \mathrm{L}^{-1}$ de TDZ) que alcançou 6,6 brotos (Figura 1A) e no $\mathrm{T}_{2}\left(\mathrm{MS}+1 \mathrm{mg} \mathrm{L}^{-1}\right.$ de TDZ), obtendo-se 4,5 brotos por explante. Os outros tratamentos não diferiram estatisticamente entre si, com exceção do $\mathrm{T}_{0}$ (testemunha) que obteve apenas 1,0 brotação por explante (Figura 1B). Jackson \&

Tabela 1. Valores médios da variável número de brotos por explante (NBE) e dados transformados em $Y=\sqrt{x+1}$, com relação à gema apical do genótipo de mamona BRS Nordestina, induzido por diferentes concentrações de TDZ

\begin{tabular}{lcl}
\hline \multicolumn{1}{c}{ Tratamentos } & NBE & $Y=$ \\
T0 - MS & 1,0 & $1,41 \mathrm{c}$ \\
T1- MS + $0,5 \mathrm{mg} \mathrm{L}^{-1}$ de TDZ & 6,6 & $2,72 \mathrm{a}$ \\
$\mathrm{T} 2$ - $\mathrm{MS}+1 \mathrm{mg} \mathrm{L}^{-1} \mathrm{de} \mathrm{TDZ}$ & 4,5 & $2,33 \mathrm{ab}$ \\
$\mathrm{T} 3$ - MS + $2 \mathrm{mg} \mathrm{L}^{-1}$ de TDZ & 4,2 & $2,27 \mathrm{~b}$ \\
$\mathrm{~T} 4$ - MS + $5 \mathrm{mg} \mathrm{L}^{-1}$ de TDZ & 2,8 & $1,95 \mathrm{~b}$ \\
T5 - MS + $10 \mathrm{mg} \mathrm{L}^{-1}$ de TDZ & 3,3 & $2,07 \mathrm{~b}$ \\
$\mathrm{~F}_{\text {tratamento }}$ & & $19,48^{* *}$ \\
CV\% & & 13,18 \\
\hline
\end{tabular}

MS - Musashige e Skoog; TDZ - tidiazuron; Médias seguidas das mesmas letras não diferem estatisticamente entre si pelo teste de Tukey a $5 \%$ de probabilidade; **Significativo $(\mathrm{p}<0,01)$ pelo teste $\mathrm{F}$

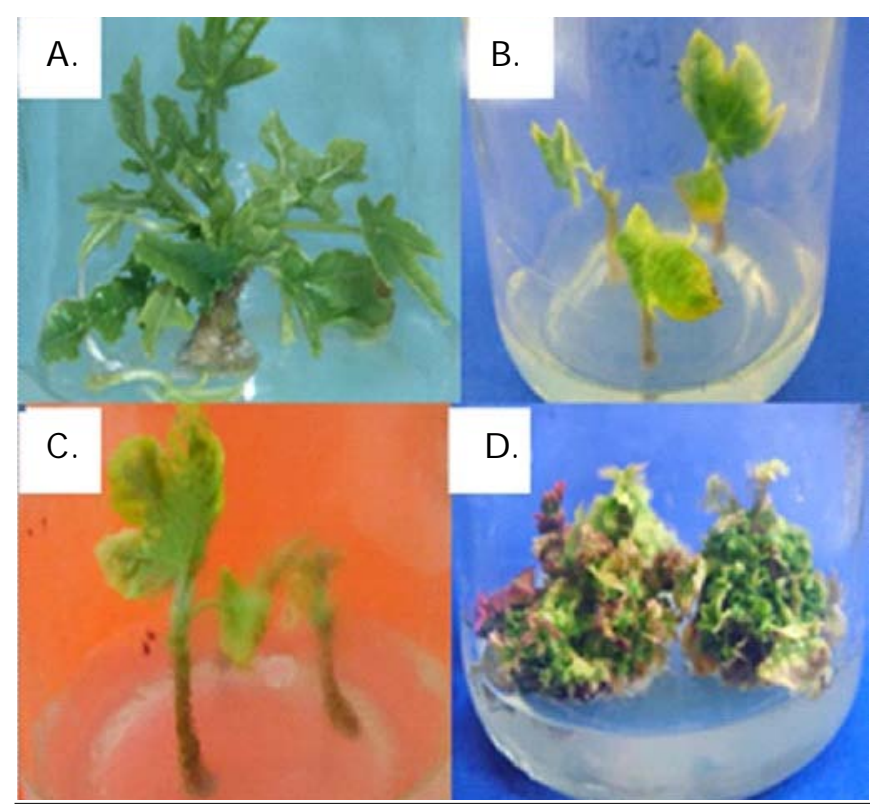

Figura 1. Indução da organo gênese no explante gema apical. A. Genótipo BRS Nordestina com multibrotação obtida por $\mathrm{T}_{1}\left(0,5 \mathrm{mg} \mathrm{L}^{-1}\right.$ de TDZ) com a formação de 6,6 brotos por explante. B e C. Tratamento $T_{0}$ (testemunha) com 1,0 broto por explante. D. Genótipo CSRN 142 com multibrotação obtida por tratamento $\mathrm{T}_{1}$ (MS + 0,5 mg L-1 de TDZ), com 16,9 brotos por explante 
Hobbs (1990) obtiveram, em um estudo similar em Pisum sativum, apenas um ou dois brotos por explante de nó cotiledonário em meio sem hormônio.

Bajaj \& Gill (1986) cultivou gemas apicais e meristemas de G. arboreum, G. hirsutum e três híbridos interespecíficos em meio MS suplementado com diferentes combinações de_AIA, CIN e BAP e notou que os meristemas cultivados em meio $\mathrm{MS}+0,5 \mathrm{mg} \mathrm{L}^{-1}$ de AIA + $2 \mathrm{mg} \mathrm{L}^{-1}$ de CIN mostraram maior desenvolvimento; as gemas apicais se alongaram formando gemas axilares, com os melhores resultados no meio com a concentração $2 \mathrm{mg} \mathrm{L}^{-1}$ de CIN.

Utilizando o fitorregulador TDZ mas em estudos com o amendoin in vitro, Kanyand et al. (1994), observaram indução de brotos antes ou durante a formação de calos, além de semelhança com este trabalho, no estudo de Rogalski et al. (2003) que utilizaram apenas uma citocinina, o BAP, na multiplicação in vitro da ameixa Santa Rosa e obtiveram bons resultados; na verdade, não ocorreram diferenças significativas no número de brotos para as diferentes concentrações de BAP testadas.

Tem-se, na Figura 2A, a análise de necrose nos múltiplos brotos constatando-se maior índice de superbrotamento com necrose e redução do tamanho dos brotos na concentração (10 $\mathrm{mg} \mathrm{L}^{-1}$ de TDZ) e a menor média de superbrotamento com necrose obtida na concentração $\left(0,5 \mathrm{mg} \mathrm{L}^{-1}\right.$ de TDZ).

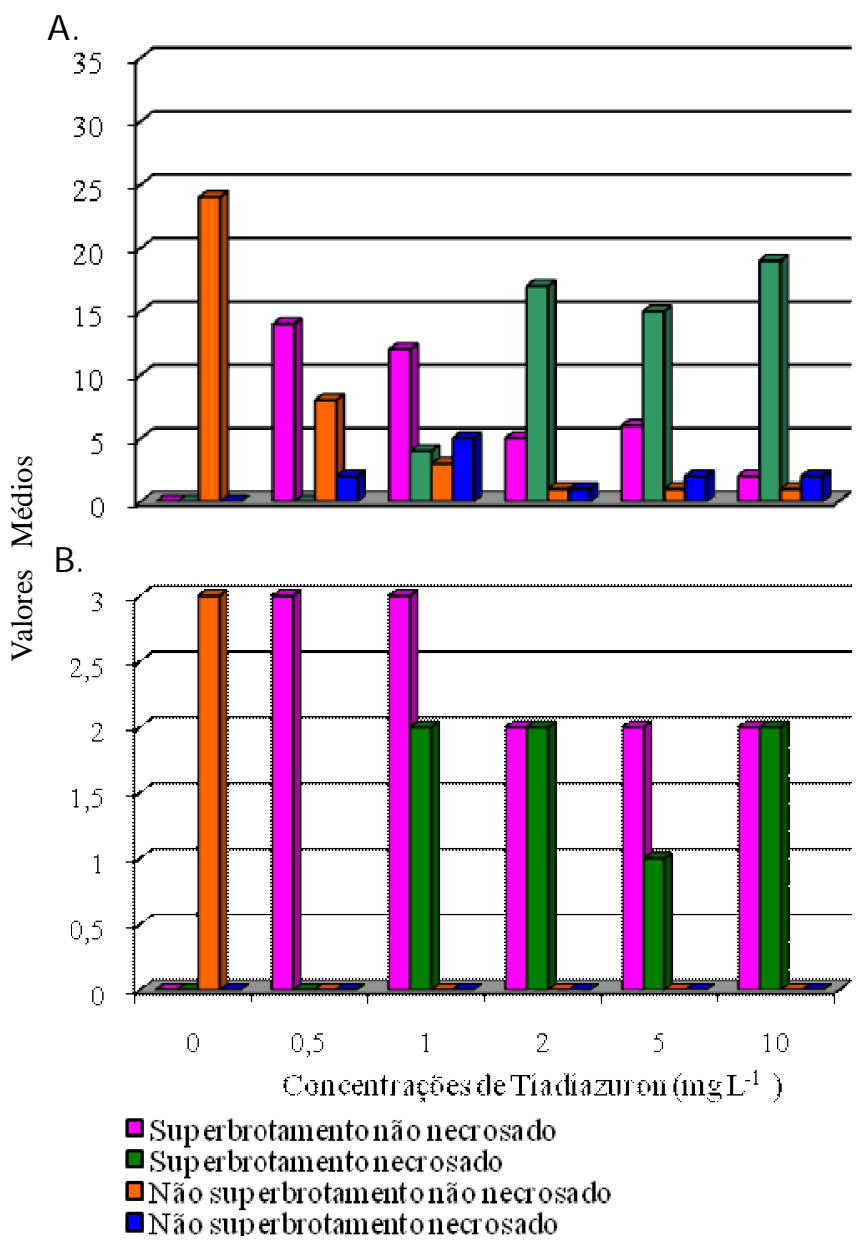

Figura 2. Representação de variáveis dos genótipos de mamona BRSN ordestina (A) e CSRN 142 (B)
Grattapaglia \& Machado (1998) observaram que, além do aspecto de toxidez, o excesso de citocinina ou a substituição por outra mais potente pode levar ao surgimento de um número demasiado de gemas adventícias, passível de ser indesejável, do ponto de vista da integridade clonal.

Andrade et al. (2005) constataram, estudando a micropropagação da aroeira, que a partir de certa concentração elevada de BAP, ocorre queda no comprimento do vegetal; da mesma maneira ocorreu neste trabalho, cujas concentrações mais elevadas de TDZ induziram brotos menores.

\section{Indução de múltiplos brotos - genótipo CSRN 142}

Os resultados das médias alcançadas na indução de número de brotos por explante (NBE) para todas as concentrações utilizadas no explante gema apical, estão apresentados na Tabela 2, na qual se constata que o $\mathrm{T}_{0}$ permaneceu não responsivo à indução de multibrotações (Figura 1C) enquanto os tratamentos $\mathrm{T}_{2}, \mathrm{~T}_{3}, \mathrm{~T}_{4}$ e $\mathrm{T}_{5}$ não diferiram significadamente entre si mas apresentaram superbrotamentos notáveis; no entanto, o $\mathrm{T}_{1}\left(\mathrm{MS}+0,5 \mathrm{mg} \mathrm{L}^{-1} \mathrm{de} \mathrm{TDZ}\right)$ apresentou efeito diferencial e promissor neste estudo, alcançando uma proliferação de 16,9 brotos por explante (Figura 1D). Constatou-se, no presente trabalho, que a menor concentração de TDZ proporcionou os melhores resultados de superbrotamento.

Tabela 2. Valores médios da variável número de brotos por explante (NBE) e dados tranformados em $Y=\sqrt{x+1}$, com relação à gema apical do genótipo de mamona CSRN 142, induzido por diferentes concentrações de TDZ

\begin{tabular}{lrc}
\hline \multicolumn{1}{c}{ Tratamentos } & NBE & $\mathbf{Y}=$ \\
$\mathrm{T}_{0}-\mathrm{MS}$ & 1,0 & $1,41 \mathrm{c}$ \\
$\mathrm{T}_{1}-\mathrm{MS}+0,5 \mathrm{mg} \mathrm{L}^{-1} \mathrm{de} \mathrm{TDZ}$ & 16,9 & $4,19 \mathrm{a}$ \\
$\mathrm{T}_{2}-\mathrm{MS}+1 \mathrm{mg} \mathrm{L}^{-1} \mathrm{de} \mathrm{TDZ}$ & 8,9 & $3,13 \mathrm{~b}$ \\
$\mathrm{~T}_{3}-\mathrm{MS}+2 \mathrm{mg} \mathrm{L}^{-1} \mathrm{de} \mathrm{TDZ}$ & 8,9 & $3,13 \mathrm{~b}$ \\
$\mathrm{~T}_{4}-\mathrm{MS}+5 \mathrm{mg} \mathrm{L}^{-1}$ de TDZ & 11,6 & $3,52 \mathrm{~b}$ \\
$\mathrm{~T}_{5}-\mathrm{MS}+10 \mathrm{mg} \mathrm{L}^{-1}$ de TDZ & 10,2 & $3,35 \mathrm{~b}$ \\
$\mathrm{~F}_{\text {tratamento }}$ & & $39,34 * *$ \\
CV\% & & 13,35 \\
\hline
\end{tabular}

MS - Musashige e Skoog; TDZ - tidiazuron; Médias seguidas das mesmas letras não diferem estatisticamente entre si pelo teste de Tukey a $5 \%$ de probabilidade; **Significativo $(\mathrm{p}<0,01)$ pelo teste $\mathrm{F}$

Neste composto do grupo das feniluréias, que desempenha atividade de citocinina, o TDZ indicou excelentes resultados. Nieuwerk et al. (1986) verificaram que este fitorregulador estimulou a multiplicação de partes aéreas da macieira, em concentração bem inferior ao BAP.

Quando brotos crescem em meio contendo citocinina, brotos axilares se desenvolvem prematuramente, resultando em ramificação precoce que, por sua vez, provoca o desenvolvimento de brotos secundários e, então, terciários, em uma mesma proliferação. As citocininas promovem o desenvolvimento de brotos e a divisão celular aumentada (Howell et al., 2003), sendo também referidas por Santos, 2003, como indutoras do superbrotamento.

O TDZ é mais ativo na multiplicação que outras citocininas, em razão do aumento da atividade da enzima fosfatase ácida que promove a interconversão nucleotídeo-nucleosídeo 
da estrutura de citocininas endógenas, tornando-as biologicamente mais ativas, e podendo manifestar-se como inibidor do crescimento, quando utilizado na mesma concentração de outras citocininas.

Percebe-se, a partir dos resultados obtidos neste trabalho, que o tipo de regulador do crescimento e as concentrações utilizadas desempenham importante papel na formação e multiplicação de brotos, interferindo na variabilidade, integridade e multiplicação do genótipo testado.

Observa-se, na Figura 2B, que as concentrações: 1,0; 2,0 e $10,0 \mathrm{mg} \mathrm{L}^{-1}$ resultaram em médias iguais de superbrotamento necrosado e na concentração $5,0 \mathrm{mg} \mathrm{L}^{-1}$ se obteve pouca necrose no superbrotamento. A concentração $\left(0,5 \mathrm{mg} \mathrm{L}^{-1} \mathrm{de}\right.$ TDZ) não ocasionou superbrotamento necrosado e se comprovou ser ela a ideal no superbrotamento sem necrose (ou sadio) de mamona. Pereira \& Fortes (2001) demonstraram, em macieira, que a característica inicial dos explantes influencia na regeneração e multiplicação in vitro deste cultivo; assim, a boa qualidade dos explantes no momento inicial do cultivo é de fundamental importância na precisão da estimativa de multiplicação, desde que se utilizem as doses ideais de fitorreguladores.

\section{Enraizamento ex vitro dos brotos}

Notou-se que, a partir dos resultados obtidos, o enraizamento ex vitro tende a produzir um sistema radicular mais completo e funcional, evitando-se a manipulação de plantas de raiz nua e tornando um processo viável à espécie Ricinus communis. Na Tabela 3 se acham expostos os valores em porcentagem, do número de plantas enraizadas (NPR) e do número de plantas mortas (NPM); constatou-se que o melhor desempenho foi no $\mathrm{T}_{2}\left(0,125 \mathrm{~g} \mathrm{~L}^{-1}\right.$ de AIA) com $75 \%$ das plantas enraizadas (Figura 3).

Tabela 3. Valores em porcentagem das variáveis número de plantas enraizadas (NPR) e número de plantas mortas (NPM) do enraizamento ex vitro de brotos de mamona produzidos in vitro

\begin{tabular}{lcc}
\hline \multicolumn{1}{c}{ Tratamentos } & \%NPR & \%NPM \\
$\mathrm{T}_{1}$ - Turfa + vermiculita + $\mathrm{H}_{2} \mathrm{O}$ & 25 & 75 \\
$\mathrm{~T}_{2}$ - Turfa + vermiculita + 0,125 g L-1 de AIA & 75 & 25 \\
$\mathrm{~T}_{3}$ - Turfa + vermiculita $+0,25 \mathrm{~g} \mathrm{~L}^{-1}$ de AIA & 25 & 75 \\
$\mathrm{~T}_{4}$ - Turfa + vermiculita $+0,5 \mathrm{~g} \mathrm{~L}^{-1}$ de AIA & 50 & 50 \\
$\mathrm{~T}_{5}$ - Turfa + vermiculita $+1 \mathrm{~g} \mathrm{~L}^{-1}$ de AIA & 50 & 50 \\
\hline
\end{tabular}

AIA -ácido 3-indoacético

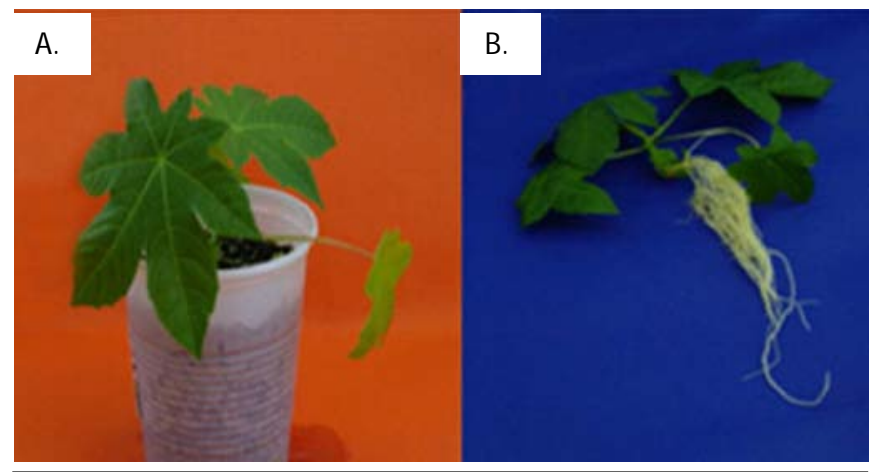

Figura 3. A. Planta micropropagada e enraizada ex vitro, obtida após 40 dias de cultivo. B. Arquitetura de raiz de planta de mamona enraizada ex vitro em $T_{2}$ (Turfa + vermiculita $+0,125 \mathrm{~g} \mathrm{~L}^{-1}$ de AIA)
A regeneração de raízes diretamente no substrato tende a produzir um sistema radicular com um número maior de raízes secundárias sem a formação intermediária de calo, que dificulta a conexão do sistema radicular entre caule e raiz (Xavier, 1997).

Observa-se semelhança desta pesquisa com o trabalho de Monette (1986), que alcançou sucesso no enraizamento de partes aéreas diretamente em substrato, após tratamento com a auxina ácido indol-3-butírico (AIB) em solução aquosa. Resultados similares aos do presente estudo também foram obtidos por Gray \& Benton (1991) que, ao estimularem o enraizamento com presença ou não de auxina, obtiveram $55 \%$ de enraizamento dos brotos de cultivares de $V$. rotundifolia, cultivadas em meio MS sem presença de auxina e $77 \%$ com indução de auxina. Diferente deste trabalho, Ahuja (1984) obteve excelentes resultados quando enraizou partes aéreas alongadas in vitro diretamente em substrato, sem aplicação de auxina.

No que se refere às plantas mortas, pôde-se perceber que a maioria teve origem de brotos menores de $2 \mathrm{~cm}$; apesar dos brotos terem passado pela fase de alongamento, nem todos alongaram o suficiente para enraizar, gerando o fato de que partes aéreas pequenas não enraizaram satisfatoriamente.

O genótipo determina diferentes respostas no estágio de micropropagação e no enraizamento, pois depende de sua condição fisiológica e das condições ambientais. DíazPérez et al. (1995) explicaram que para a sobrevivência da planta no estágio de enraizamento ex vitro, é necessário que ela produza novas raízes em substratos porosos, as quais forneçam condições favoráveis para a nutrição da planta, além de desenvolver os mecanismos de controle de transpiração.

Grattapaglia \& Machado (1998) constataram que a homogeneidade e a qualidade das plantas determinam, em grande parte, o sucesso na fase de enraizamento ex vitro. Se a juvenilidade e o alongamento forem preservados nas brotações regeneradas in vitro, estas poderão facilmente ser enraizadas ex vitro.

\section{CONCLUSÕES}

1. Os tratamentos suplementados com a citocinina TDZ induzem ao superbrotamento no explante gema apical, para os dois genótipos.

2. Tratamentos sem o fitorregulador TDZ não induzem múltiplos brotos.

3._A concentração de $0,5 \mathrm{mg} \mathrm{L}^{-1}$ de TDZ proporcionou melhor capacidade organogênica com satisfatória proliferação de brotos.

4. O enraizamento ex vitro dos brotos é recomendável para a mamoneira.

5. A concentração de $0,125 \mathrm{~g} \mathrm{~L}^{-1}$ de AIA aplicada ex vitro nas brotações produzidas in vitro, possibilitou a melhor produção de raízes, com a obtenção de $75 \%$ de plantas enraizadas. 


\section{AGRADECIMENTOS}

Os autores agradecem à Embrapa Algodão e ao CNPq, pelo apoio e financiamento.

\section{LITERATURA CITADA}

Ahuja, M. R. A. Commercially feasible micropropagation method for aspen. Silvae Genetic, v.33, p.4-5, 1984.

Alves, E. C. S. de C.; Xavier, A.; Otoni, W. C. Organogênese de explante foliar de clones de eucalyptus grandis $\mathrm{x}$ e. urophylla. Pesquisa Agropecuária Brasileira, v.39, n.5, p.421-430, 2004.

Andrade, M.W.; Luz, J. M. Q.; Lacerda, A. S.; Melo, P. R. A. Micropropagação da aroeira (Myracrodruon Urundeuva Fr. All). http:/ /www.editora.ufla.br/revista/24.1/art.21.htm-8k. 10 Jun. 2005.

Bajaj, Y. P. S.; Gill, M. Preservation of cotton (Grossypium spp.) through shoot tip and meristem culture. Indian Journal of Experimental Biology, v.24, p.581-583, 1986.

Beltrão, N. E. de M.; Melo, F. B.; Cardoso, G. D.; Severino, L. S. Mamona: Árvore do conhecimento e sistemas de produção para o semiárido brasileiro. Campina Grande: Embrapa Algodão, 2003. 19p. Circular Técnica, 70.

Carvalho, J. M. F. C. Técnicas de micropropagação. Campina Grande: Embrapa Algodão, 1999. 39p. Documentos, 64.

Carvalho, J. M. F. C. Germinação e contaminação de sementes de mamoneira in vitro mediante quebra de dormência e desinfecção. Revista de Oleaginosas e Fibrosas, v.6, n.1, p.483-490, 2002.

Carvalho, J. M. F. C.; Furtado, C. M.; Silva, H.; Castro, J. P de. Metodologia para o superbrotamento de amendoin (Arachis hipogaea) através do cultivo "in vitro". Campina Grande: Embrapa Algodão, 2003. 3p. Comunicado Técnico, 196.

Díaz-Pérez, J. C.; Sutter, E. G.; Shackel, K. A. Acclimatisation and subsequent gasexchange, water relations, survival and growth of microcultured apple plantlets after transplanting them in soil. Physiologia Plantarum, v.95, n.2, p. 225-232, 1995.

Furtado, C. M.; Carvalho, J. M. F. C.; Castro, J. P. de; Silva, H. Comparação da frequiência de regeneração in vitro do amendoim (Arachis hipogaea), utilizando diferentes citocininas. Revista de Biologia e Ciências da Terra, v.7, n.1, p. 51-58, 2007.

Grattapaglia, D.; Machado, M. A. Micropropagação. In: Torres, A. C.; Caldas, L. S.; Buso, J. A. (ed.). Cultura de tecidos_e transformação genética. Brasília: Embrapa-SPI/EmbrapaCNPH, v.1, 1998. p.183-260.

Gray, D. J.; Benton, C. M. In vitro micropropagation and plant establishment of muscadine grape cultivars (Vitis rotundifolia). Plant Cell, Tissue and Organ Culture, v.27, n.1,.p.7-14. 1991.
Howell, S. H.; Lall, S.; Che, P. Cytokinins and shoot development. Trends in Plant Science, v.8, p.453-459, 2003.

Jackson, J. A.; Hobbs, S. L. A. Rapid multiple shoot production from cotyledonary node explants of pea (Pisum sativum). In Vitro Cell Developmental Biology, v.26, p. 835-838, 1990.

Kanyand, M.; Dessai, A. P.; Prakash, C. S. Thidiazuron promotes high frequency regeneration of peanut (Arachis hipogaea) plants in vitro. Plant Cell Reports, v.14. p.1-5, 1994.

Leifert, C.; Ritchie, J. Y.; Waites, W. M. Contaminants of plant tissue and cell cultures. World Journal of Microbiology and Biotechnology, v.7, p.452-469, 1991.

Milani, M.; Nóbrega, M. B. M.; Suassuna, N. D.; Coutinho, W. M. Resistência da mamoneira (Ricinus communis L.) ao mofo cinzento causado por Amphobotrys ricini. Campina Grande: Embrapa Algodão, 2005. 22p. Documentos, 137.

Monette, P. L. Micropropagation of kiwifruit using non-axenic shoot tips. Plant Cell, Tissue and Organ Culture, v.6,p.7382,1986 .

Murashige, T.; Skoog, F. A revised medium for rapid growth and bio-assays with tobacco tissue culture. Physiologia Plantarum, v.5, p.473-497. 1962.

Nieuwkerk, J. D.; Zimmerman, R. H.; Fordham, I. Thidiazuron stimulation of apple shoot proliferation in vitro. Hort Science, v.21, p.516-518, 1986.

Pereira, J. E. S.; Fortes, G. R. L. Multiplicação e aclimatização da macieira influenciada pelo tipo de explante e pelo tempo de permanência em meio de cultura de enraizamento. Revista Brasileira de Fruticultura, v.23, n.2, p.417-420, 2001.

Rocha, M. S.; Oliveira, K. C. de; Costa, M. N. da; Cunha, A. O.; Carvalho, J. M. F. C.; Santos, J. W. dos. Métodos de regeneração in vitro da mamoneira a partir de diferentes tipos de explantes. Revista Brasileira de Oleaginosas e Fibrosas, v.7, n.1, p.647-652, 2003.

Rogalski, M.; Guerra, M. P.; Silva, A. L. da. Multiplicação in vitro da ameixeira "Santa Rosa": Efeito da citocinina BAP. Revista Brasileira de Fruticultura, v.25, n.2, p.365-36, 2003.

Santos, E. K. dos. Totipotência celular e cultura de tecidos vegetais. In: Freitas, L.B.; Bered, F.(ed.). Genética e evolução vegetal. Porto Alegre: UFRGS, 2003. p.415-444.

SAS/STAT User's Guide. In: SAS Institute. SAS Onlinedoc: Version 8.2, Cary 2000. CD Rom

Sugiyama, M. Organogenesis in vitro. Current Opinion in Plant Biology, v.2, p.61-64, 1999.

Xavier, A.; Comério, J. Enraizamento ex vitro de gemas de Eucalyptus spp. multiplicadas e alongadas in vitro. Scientia Forestalis, v.20, n.51, p.29-36, 1997. 